\title{
The prognostic role of steroid hormone receptor signaling pathways in urothelial carcinoma
}

\author{
Yujiro Nagata ${ }^{1,2,3}$, Hiroshi Miyamoto ${ }^{1,2,4}$ \\ ${ }^{1}$ Department of Pathology \& Laboratory Medicine, ${ }^{2}$ James P. Wilmot Cancer Institute, University of Rochester Medical Center, Rochester, NY, \\ USA; ${ }^{3}$ Department of Urology, University of Occupational and Environmental Health School of Medicine, Kitakyushu, Japan; ${ }^{4}$ Department of \\ Urology, University of Rochester Medical Center, Rochester, NY, USA \\ Contributions: (I) Conception and design: All authors; (II) Administrative support: None; (III) Provision of study materials or patients: None; (IV) \\ Collection and assembly of data: None; (V) Data analysis and Interpretation: None; (VI) Manuscript writing: All authors; (VII) Final approval of \\ manuscript: All authors. \\ Correspondence to: Hiroshi Miyamoto, MD, PhD. Department of Pathology \& Laboratory Medicine, University of Rochester Medical Center, 601 \\ Elmwood Avenue, Box 626, Rochester, NY 14642, USA. Email: hiroshi_miyamoto@urmc.rochester.edu.
}

\begin{abstract}
Emerging preclinical or clinical evidence suggests a vital role of nuclear receptor-mediated signals in modulating urothelial carcinogenesis and cancer growth. These include, but are not limited to, androgen receptor, estrogen receptors, glucocorticoid receptor, progesterone receptor, vitamin D receptor, retinoid receptors, and peroxisome proliferator-activated receptors, as well as orphan receptors. In particular, immunohistochemical studies in surgical specimens have demonstrated that increased or decreased expression of steroid hormone receptors, as well as alterations of their upstream or downstream signaling pathways, is often associated with oncologic outcomes in patients with bladder or upper urinary tract cancer. This review article summarizes and discusses available data indicating that steroid hormone receptors and related signals serve as biomarkers for urothelial tumors which further predict their recurrence and/or progression.
\end{abstract}

Keywords: Androgen; estrogen; glucocorticoid; progesterone

Submitted Nov 27, 2019. Accepted for publication Jan 02, 2020.

doi: $10.21037 /$ tcr.2020.01.06

View this article at: http://dx.doi.org/10.21037/tcr.2020.01.06

\section{Introduction}

Urinary bladder cancer, which is mostly a urothelial carcinoma, is one of the most commonly diagnosed neoplasms, with nearly 550,000 new cases and 200,000 deaths estimated in 2018 throughout the world (1). In addition to the bladder (and the urethra), urothelial carcinoma occurs in the upper urinary tract (UUT) composed of the pyelocaliceal system and the ureter. Although urine cytology remains the most accurate non-invasive test for detecting urothelial carcinoma, no screening test has been recommended for its early detection. Meanwhile, no biomarkers that provide precise prognostic information are available. Strikingly, the prognosis in patients with urothelial carcinoma has not significantly improved after decades of therapeutic advances. Specifically, the Surveillance, Epidemiology, and End Results (SEER) database showed that the 5 -year relative survival rates for those diagnosed with bladder cancer in 1975-1977 and 2009-2015 were $72.3 \%$ and $78.3 \%$, respectively (2).

A variety of molecules, including transcription factors, as well as their upstream and downstream pathways, have been implicated in urothelial cancer outgrowth. In particular, current evidence indicates the involvement of the nuclear receptor superfamily-mediated signals in the development and progression of urothelial cancer. These receptors include, but are not limited to, androgen receptor (AR), estrogen receptor- $\alpha(\mathrm{ER} \alpha), \mathrm{ER} \beta$, glucocorticoid receptor (GR), progesterone receptor (PR), vitamin D receptor (VDR), retinoid receptors [e.g., retinoic acid receptor 
(RAR), retinoid $X$ receptor (RXR)], and peroxisome proliferator-activated receptors (e.g., $\operatorname{PPAR} \gamma$ ), as well as orphan receptors. These observations have thus provided novel therapeutic targets for urothelial carcinoma. Of note, recent studies have addressed the role of nuclear receptor signals and related pathways, as diagnostic and/or prognostic biomarkers, in urothelial tumors. In this article, we review the results mainly from immunohistochemical studies in surgical specimens demonstrating the relationship between alterations of steroid hormone receptors, including sex hormone receptors (3-27) and GR (15,28), as well as other members of nuclear receptors, in urothelial tumors and longterm oncologic outcomes (online: http://cdn.amegroups. $\mathrm{cn} / \mathrm{static} /$ application/4519bb9f737b56688eb5bc85f1d6fd 3c/tcr.2020.01.06-1.pdf). We additionally highlight several molecules whose expression is modulated via the $\mathrm{AR}$ and/or ER pathways in urothelial cells.

\section{AR}

Preclinical findings have suggested that androgen-mediated $\mathrm{AR}$ activation is associated with the promotion of urothelial tumorigenesis [reviewed in (29)], which may clearly explain the male dominance in the incidence of bladder cancer. Accordingly, as documented in retrospective studies (30-33), androgen deprivation therapy, which has primarily been used in the treatment of advanced prostate cancer, is anticipated to prevent the recurrence of non-muscle-invasive (NMI) bladder tumors following transurethral surgery, or otherwise, the tumor development in high-risk populations. The authors' group has also demonstrated in vitro and in vivo data indicating that $\mathrm{AR}$ activation correlates with urothelial cancer progression which is a pathological event/ process distinct from carcinogenesis or cancer initiation [reviewed in (29); more recent findings in $(34,35)$ ].

Immunohistochemistry in surgical specimens has shown that the positive rates of AR expression in bladder or UUT urothelial tumors range from $11 \%$ to $55 \%$ (3-17, $19,20)$. In most of the comparative studies $(3-5,9,15)$, AR positivity in urothelial tumors was significantly lower than that in control/normal urothelial tissues. However, three of the studies demonstrated no AR expression in nonneoplastic urothelium $(8,12,17)$. Similarly, some of the studies demonstrated down-regulation of AR expression in high-grade or muscle-invasive (MI) tumors, compared with low-grade or NMI tumors, respectively $(3-5,7-10,14)$. Interestingly, all of the studies, except for one (19), have shown no significant differences in AR expression between urothelial tumors from male versus female patients.

The prognostic impact of immunoreactivity for $A R$ in urothelial tumors remains controversial. In spite of the promoting properties of AR signals in urothelial tumorigenesis, three studies demonstrated a significant association $(13,20)$ or a tendency $(8)$ between $\mathrm{AR}$ expression and a lower risk for the recurrence of bladder tumor after surgery. In addition, a meta-analysis of 3 immunohistochemical studies involving 496 patients revealed a significantly lower risk of disease recurrence in those with AR-positive NMI bladder tumor, compared with AR-negative tumors [hazard ration $(\mathrm{HR})=0.593$; $\mathrm{P}=0.006]$ (36). By contrast, AR expression was strongly (12) or marginally (9) associated with the tumor progression in two studies, while others failed to reveal its prognostic significance in patients with bladder cancer. None of the immunohistochemical studies in patients with UUT tumor have shown significant associations of AR expression with their prognosis. Additionally, in relatively small cohorts of patients with bladder cancer, AR expression has been shown to be associated with resistance to neoadjuvant chemotherapy (37) or intravesical BCG immunotherapy (38).

The prognostic value of $A R$ gene expression in bladder cancer has also been investigated in two studies using a quantitative polymerase chain reaction (PCR) method. In $M I$ bladder cancers from patients undergoing radical cystectomy, high $A R$ expression was significantly associated with worse recurrence-free survival $(\mathrm{P}=0.005)$ or diseasespecific survival ( $\mathrm{P}=0.001)$ (39). In the other study, $A R$ expression was significantly elevated in NMI tumors, compared with MI tumors ( $\mathrm{P}=0.0004)$, and was found to be an independent prognosticator for disease-free survival [likelihood ratio (LR) $\mathrm{Chi}^{2}=7.23 ; \mathrm{P}=0.007$ ] or overall survival $\left(\mathrm{LR} \mathrm{Chi}^{2}=4.32 ; \mathrm{P}=0.04\right)$ in female patients (40).

\section{ERs}

It has been documented that estrogens both induce and inhibit urothelial cancer outgrowth, and their effects appear to be cell-specific and otherwise dependent on the functional activity of ER $\alpha$ and ER $\beta$ as well as G proteincoupled estrogen receptor 1 (GPER)/G protein-coupled receptor 30 (GPR30) (41-49). For instance, bladder cancer was significantly more frequently detected in $\mathrm{N}$-butyl- $\mathrm{N}$ (4-hydroxybutyl) nitrosamine-treated female ER $\alpha$ knockout mice, compared with female wild-type littermates, implying the preventive role of ER $\alpha$ in tumor development (48). However, estrogens were shown to promote the cell 
proliferation of a urothelial cancer line predominantly via the ER $\alpha$ pathway as well as that of primary urothelium line predominantly via the ER $\beta$ pathway (44), while selective ER modulators, such as tamoxifen and raloxifene, suppressed the cell growth of bladder cancer lines expressing the ER $\beta(41,43)$.

$\mathrm{ER} \alpha$ protein has been immunohistochemically detected only in a small subset (e.g., 1-5\%) of bladder cancer samples (12,21-23). Nonetheless, a PCR-based study demonstrated that $E R \alpha$ gene was positive in all of the 10 bladder tumors examined, which was even greater (2.77fold) than in corresponding normal tissues (44). Our immunohistochemical analyses also demonstrated relatively high rates of $\mathrm{ER} \alpha$ positivity in bladder [i.e., $27 \%$ (9) or $31 \%$ (of NMI tumors) (32)] and UUT [i.e., 18\% (15)] tumors. Unlike the PCR data described above (44), the levels of $\mathrm{ER} \alpha$ protein expression in non-neoplastic urothelial tissues were elevated, compared with those in urothelial cancer $(9,15,22,32)$. At least two of these immunohistochemical studies also revealed that ER $\alpha$ expression was downregulated in higher grade or more invasive tumors $(9,22)$. However, no studies have indicated the prognostic value of ER $\alpha$ expression in patients with urothelial cancer. Instead, the status of $E R \alpha$ expression in radical cystectomy specimens could further stratify those with low $A R$ tumor into subgroups with significantly poorer outcomes (39).

In some of studies $(8-10,15,21,24,25,32), 22-76 \%$ of urothelial tumors were found to be immunoreactive for $\mathrm{ER} \beta$, which was significantly lower than the positive rates in non-neoplastic urothelial tissues. More recently, ER $\beta$ was shown to be immunohistochemically positive in all of the 410 bladder tumors examined (23). In addition, ER $\beta$ expression was significantly up-regulated $(9,13,21,24)$ or down-regulated (25) in higher grade/stage tumors. Elevated ER $\beta$ expression in bladder tumors was also associated with higher risks for disease recurrence and/or progression $(8,9,26)$. In one of the studies (8), ER $\beta$ positivity was reported to be an independent predictor $(\mathrm{HR}=11.663$; $\mathrm{P}=0.025)$ for the progression of non-invasive bladder tumors (8). The meta-analysis of 3 immunohistochemical studies further revealed associations between $\operatorname{ER} \beta$ positivity in NMI bladder tumors and a lower recurrence-free $(\mathrm{HR}=1.573 ; \mathrm{P}=0.013)$ or progression-free $(\mathrm{HR}=2.236$; $\mathrm{P}=0.089$ ) survival rate (36). Conversely, a strong association between ER $\beta$ overexpression and favorable prognosis was demonstrated in at least three studies $(13,23,27)$.

\section{GR}

It remains controversial whether glucocorticoids induce versus inhibit urothelial tumorigenesis. A case-control study demonstrated that prolonged use of glucocorticoids was associated with an elevated incidence of bladder cancer (50), presumably via immunosuppression. By contrast, our recent study has revealed that a synthetic glucocorticoid prednisone prevents the malignant transformation of GR-positive urothelial cells, but not that of GR-negative cells (51). Prednisone and other natural or synthetic glucocorticoids, such as corticosterone and dexamethasone, have also shown to strongly inhibit bladder cancer cell invasion and metastasis via, for instance, inactivating NF$\kappa \mathrm{B}$ (52-54). However, treatment with dexamethasone (and most of other glucocorticoids examined) in bladder cancer lines resulted in increases in cell viability and decreases in apoptosis particularly that induced by a widely used chemotherapeutic medication, cisplatin. Apart from glucocorticoid-induced immunosuppression, glucocorticoid-mediated GR signals appear to have dual roles (i.e., inhibition of tumor development and progression versus promotion of cell proliferation) in urothelial cancer. Further studies have indicated that the action of glucocorticoids may be dependent on a balance between transactivation and transrepression of GR $(51,54,55)$ that involve their therapeutic effects and associated adverse effects, respectively. In particular, transrepression appears to correlate with the function of GR as a tumor suppressor.

Our immunohistochemical analyses in bladder (28) and UUT (15) tumors have demonstrated that GR is expressed in most of non-neoplastic urothelial tissues, which is down-regulated in urothelial neoplasms. The levels of GR expression were also significantly lower in high-grade or MI bladder tumors than in low-grade or NMI tumors (28). However, there were no significant differences in GR positivity between low-grade versus highgrade or NMI versus MI UUT tumors (15). In addition, loss of GR expression was associated with the recurrence of NMI bladder tumors and the progression of MI bladder tumors (28). Multivariate analysis further identified low GR expression as a predictor for the recurrence of NMI tumors $(\mathrm{HR}=2.252 ; \mathrm{P}=0.034)$ and the progression of $\mathrm{MI}$ tumors $(\mathrm{HR}=3.690 ; \mathrm{P}=0.077)$ (28). The levels of GR expression in UUT tumors were not strongly associated with patient 
outcomes in our study (15).

\section{PR}

A case-control study demonstrated a significantly lowered risk of developing bladder cancer in multiparous women or those using oral contraceptives (56). Using a transgenic model for bladder cancer, multiparous female mice were also found to develop significantly smaller tumors than nulliparous females (57). These findings suggested that not only estrogens but also progestogens could prevent urothelial tumorigenesis.

Using hormone-binding assay, PR was shown to be positive in 1 of 3 non-invasive and 3 of 3 advanced urothelial tumors (58). An immunohistochemical study then detected immunoreactivity for PR in 18 of 20 bladder tissues from boys aged 1-12 years (59). However, subsequent larger immunohistochemical studies failed to detect PR signals in 198 (22) and 410 (23) cases of bladder cancer. Another study, using 120 cases of surgical specimens, showed PR expression in $2 \%$ of non-neoplastic bladders and $4 \%$ of bladder cancer tissues (12). More recently, we demonstrated that PR was positive in $13 \%$ of control urothelial tissues from the UUT and $16(16 \%)$ of 99 UUT tumors (15). Although the levels of PR expression were not significantly altered in lowgrade versus high-grade or NMI versus MI UUT tumors in our study, PR positivity in pT3-4 tumors was associated with a significantly higher risk of disease-specific mortality. Moreover, patients with ER $\alpha$-positive and/or PR-positive pT3-4 UUT tumor had a significantly higher risk of disease-specific mortality, and positivity of either ER $\alpha$ or $\mathrm{PR}$, or both was an independent prognosticator $(\mathrm{HR}=2.434$; $\mathrm{P}=0.037)$ in this subgroup of patients. In support of our data (15), the status of $E R \alpha$ and $P R$ expression in MI bladder cancers was shown to help stratifying a subgroup of patients into those with significantly poorer outcomes (39).

\section{Other members of nuclear receptors}

The mRNA or protein expression of other nuclear receptors, including VDR, RAR $\alpha, \operatorname{RAR} \beta 2, \operatorname{RAR} \gamma, \operatorname{RXR} \alpha$, and PPAR $\gamma$, as well as a few orphan receptors, has been investigated in urothelial cancer specimens.

Although controversial data exist (60), low serum levels of vitamin $\mathrm{D}$ (61), as well as $V D R$ gene polymorphisms (62) associated with reduced receptor activity, have been implicated in the risk of developing bladder cancer. Using preclinical models, vitamin $\mathrm{D}$ was also shown to prevent the development of chemical carcinogen-induced bladder tumors and suppress the cell growth of VDR-positive bladder cancer lines (63). Thus, VDR signaling appears to function as a tumor suppressor for urothelial cancer. Immunohistochemical studies in surgical specimens demonstrated that VDR was positive in $86-100 \%$ of bladder tumors (64-66), which was significantly higher (65) vs. lower (66) than the VDR-positive rate in normal urothelial cells. In addition, the levels of VDR expression were higher in high-grade or MI tumors (64) vs. the lowest in more advanced (pT2b-4) or metastatic cases (66). The outcome analysis also showed strong associations between elevation (65) vs. loss (66) of VDR expression and poorer prognosis.

A meta-analysis of 25 studies assessing the preventive effects of retinoic acids on bladder cancer development demonstrated an inverse association of dietary intake of vitamin $\mathrm{A} /$ retinol with its risk (67). In preclinical models, retinoids have been shown to inhibit the development of carcinogen-induced bladder cancer in animals (68) and the proliferation of bladder cancer cells (69). A study using a PCR-based method showed that all of the normal bladders or NMI bladder tumors examined expressed the retinoid receptors, while some of MI bladder tumors lost RAR $\alpha(60 \%), \operatorname{RAR} \gamma(20 \%)$, and RXR $\alpha$ (40\%) (70). In addition, RAR $\beta 2$ was found to be positive in $100 \%$ of normal bladder specimens, $50 \%$ of NMI tumors, and $40 \%$ of MI tumors (70). However, no studies have assessed associations of retinoid receptor expression in urothelial tumors with patient outcomes. Instead, it was shown that the frequency of RAR $\beta$ promoter methylation in 36 cases of noninvasive low-grade papillary urothelial carcinoma was not statistically different between those with (16\%) versus without (29\%) tumor recurrence following transurethral surgery (71).

Although debatable, the use of pioglitazone, a PPAR agonist prescribed as an anti-diabetes medication, has been linked to an increased risk of developing bladder cancer $(72,73)$. Treatment with a PPAR $\gamma$ agonist rosiglitazone or overexpression of PPAR $\gamma$ in bladder cancer lines was also found to result in significant induction of cell migration and invasion (74), whereas PPAR $\gamma$ agonists conversely showed inhibitory $(75,76)$ or no stimulatory $(77)$ effects on cell growth. These findings may indicate the presence of multiple mechanisms for the induction/suppression of urothelial tumor outgrowth by $\operatorname{PPAR} \gamma$ signals and/or the effects of PPAR $\gamma$ agonists via the non-PPAR $\gamma$ pathways. Amplification of PPAR $\gamma$ gene has been documented in bladder cancer specimens (74), but there have been no studies showing PPAR $\gamma$ expression in urothelial tumors.

$\mathrm{Up}$ - or down-regulation of the expression of several 
Table 1 Molecules whose expression is modulated via sex hormone receptor-mediated signaling in urothelial cells

\begin{tabular}{|c|c|c|c|c|}
\hline & $\begin{array}{l}\text { Associated } \\
\text { receptor (s) }\end{array}$ & Hormone effect on the expression & $\begin{array}{l}\text { Consequence for urothelial cancer } \\
\text { outgrowth }\end{array}$ & Reference \\
\hline Akt & $\mathrm{AR} / \mathrm{ER} \alpha$ & Up-regulation/down-regulation & Stimulation & $(48,83)$ \\
\hline ATF2 & AR & Up-regulation & Stimulation & (35) \\
\hline$\beta$-catenin & $A R$ & Up-regulation & Stimulation & $(17,84,85)$ \\
\hline CD24 & AR & Up-regulation & Stimulation & $(87,88)$ \\
\hline c-myc & AR & Up-regulation & Stimulation & (89) \\
\hline cyclin D1 & AR & Up-regulation & Stimulation & (86) \\
\hline cyclin D3 & AR & Up-regulation & Stimulation & (89) \\
\hline ELK1 & AR & Up-regulation & Stimulation & $(90,91)$ \\
\hline ERBB2 & AR & Up-regulation & Stimulation & (83) \\
\hline ERK1/2 & AR & Up-regulation & Stimulation & (83) \\
\hline FGFR3 & AR & Up-regulation & Stimulation & (89) \\
\hline GATA3 & $\mathrm{AR} / \mathrm{ER} \beta$ & Down-regulation/up-regulation & Inhibition & (89) \\
\hline INPP4B & $\mathrm{ER} \alpha$ & Up-regulation & Inhibition & $(48)$ \\
\hline MMP-9 & AR & Up-regulation & Stimulation & (86) \\
\hline UGT1A & $\mathrm{AR} / \mathrm{ER} \beta$ & Down-regulation/up-regulation & Inhibition & $(47,93)$ \\
\hline
\end{tabular}

orphan receptors in bladder cancer tissues, compared with paired normal bladders, has been demonstrated. Of these receptors, HNF4G expression was most frequently elevated in tumors, and its overexpression in bladder cancer cells resulted in the promotion of tumor growth $(78,79)$. Nurr1 was also found to be often overexpressed in bladder cancers and was associated with the induction of tumor cell migration $(78,80)$. Indeed, in an immunohistochemical study, the expression levels of Nurr1 were significantly elevated in higher grade/stage tumors, and high cytoplasmic Nurr 1 expression, but not total expression, was found to be an independent predictor of cancer-specific mortality (HR=4.894; $\mathrm{P}<0.001)$ (80). Similarly, Nur77 was overexpressed especially in MI bladder tumors $(78,81)$, while Nur77 activation resulted in the delay of tumor growth in cell lines and animal models $(81,82)$.

\section{Molecules whose expression is modulated via steroid hormone receptor signals}

An increasing amount of evidence suggests the involvement of upstream pathways and downstream effectors of steroid hormone receptor-mediated signals in urothelial cancer outgrowth. Table 1 summarizes such molecules directly or 
indirectly regulated via the AR and/or ER pathway(s). The following are key molecules, including several transcription factors, whose expression has been not only shown to be up- or down-regulated via androgen-mediated AR and/or estrogen-mediated ER pathways in bladder cancer cells but also assessed their prognostic role in surgical specimens.

ATF2, a member of the leucine zipper family of DNA-binding proteins, is normally activated via its phosphorylation in response to phospho-ERK/MAPK signals. We have recently demonstrated that androgens activate ATF2 in both neoplastic and non-neoplastic urothelial cells expressing the AR and that ATF2 activation results in the promotion of urothelial tumorigenesis and tumor progression (35). In our immunohistochemistry in a set of bladder tissue microarray, the levels of ATF2/ phospho-ATF2/phospho-ERK expression were significantly higher in tumors than in non-neoplastic urothelial tissues. Moreover, ATF2 expression was significantly elevated in high-grade and MI tumors, compared with lower grade and NMI tumors, respectively. Univariate analysis showed that patients with phospho-ATF2-positive or phosphoERK-positive MI tumor had significantly higher risks of disease progression. Multivariate analysis further showed that phospho-ATF2 positivity $(\mathrm{HR}=5.317 ; \mathrm{P}=0.012)$ and phospho-ERK positivity $(\mathrm{HR}=2.727 ; \mathrm{P}=0.066)$ were associated with a lower cancer-specific survival rate. In addition, moderate/strong expression of ATF2 was an independent predictor for the recurrence of low-grade tumors following transurethral surgery $(\mathrm{HR}=2.956$, $\mathrm{P}=0.045)$.

$\beta$-catenin is an integral component of the Wnt signaling pathway which is known to activate target genes, including a proto-oncogene $c-m y c$, a cell cycle regulator cyclin D1, and a receptor tyrosine kinase receptor epidermal growth factor receptor $(E G F R)$. AR signals have been shown to activate the $W n t / \beta$-catenin signaling in bladder cancer cells $(84,85)$. Co-expression of $\mathrm{AR}$ and $\beta$-catenin in the nuclei of bladder cancer cells was also documented (84). However, conflicting data exist in regard to an association between the status of $\beta$-catenin expression in bladder cancer and tumor behavior. Nonetheless, various studies demonstrated loss or reduced membranous staining of $\beta$-catenin in bladder cancer, compared with normal urothelium, and in higher grade/ stage tumors, as well as nuclear $\beta$-catenin accumulation, as a hallmark of $\mathrm{Wnt} / \beta$-catenin activation, in tumors, some of which were further associated with worse patient outcomes $(17,84,94-97)$. In particular, aberrant expression of $\beta$-catenin in bladder cancer was found to be an independent factor of disease recurrence or progression (17). More specifically, nuclear $\beta$-catenin expression was an independent predictor of the recurrence $(\mathrm{HR}=5.851 ; \mathrm{P}=0.002)$ or progression (HR=3.104; $\mathrm{P}=0.034)$ of NMI tumors (97).

CD24, a cell surface protein which functions as a cell adhesion molecule, has been shown to promote the development of urothelial tumor and its metastasis $(87,98)$. Additionally, in bladder cancer cells, androgens activate CD24 via the AR pathway $(87,98)$. Immunohistochemical studies have shown CD24 expression exclusively in bladder cancer cells, but not in adjacent stromal cells (98-100). Significantly elevated CD24 expression was also observed in higher grade/stage tumors, compared with lower grade/ stage tumors $(99,100)$, as well as in metastatic tumors, compared with primary tumors (98). Moreover, univariate analysis revealed associations between CD24 overexpression and the recurrence of NMI tumors (100) or cancer-specific mortality in patients with MI tumor (99). However, CD24 was found to be not an independent prognosticator (99).

The ErbB family, consisting of ERBB1/EGFR, ERBB2/ HER2, ERBB3, and ERBB4, is a class of receptor tyrosine kinases that are well known to regulate survival signaling in urothelial cancer cells. Indeed, the efficacy of EGFRtargeted therapy has been assessed in bladder cancer (101). We have demonstrated that androgens induce the expression of EGFR and ERBB2, as well as phosphorylation of their downstream proteins Akt and ERK, in AR-positive bladder cancer cells (83), while EGF promotes their growth via modulating AR activity (102). Alterations of the ErbB family, including protein overexpression and gene amplification/ mutation, have also been investigated in bladder cancer tissues, providing mixed results as to their prognostic significance (101,103-107). For example, some studies indicated ERBB2 overexpression as a poor prognosticator, while others failed to do. Meanwhile, EGFR or ERBB2 expression was shown to be up-regulated in MI bladder tumors in most of the studies. In a most recent metaanalysis of 9 studies involving 2,242 patients (104), ERBB2 expression was associated with poorer cancer-specific survival (HR=2.00; $\mathrm{P}=0.006)$.

ELK1, a member of the ETS-domain family of transcription factors, has been implicated in cell proliferation or cell cycle control, as well as apoptosis, via regulating the expression of various genes, including a protooncogene $c$-fos. Interestingly, the induction of urothelial tumorigenesis and tumor progression by ELK1 signals has been shown to be primarily AR-dependent $(90,91,108)$. Androgens have also been found to activate ELK1 in both 
non-neoplastic (91) and urothelial cancer (90) cells. Our immunohistochemical analyses revealed considerable induction in the expression levels of ELK1, as well as its activated form, phospho-ELK1, in bladder tumors, compared with non-neoplastic urothelial tissues (90). As expected, the expression of ELK1 or phospho-ELK1 versus $A R$ in bladder tumors was significantly correlated. Although no strong associations between the levels of ELK1/phospho-ELK1 expression and tumor grades or stages were observed, positivity of phospho-ELK1 expression in NMI or MI tumors precisely predicted their recurrence or progression, respectively. Multivariate analysis further showed an association between phosphoELK1 expression and cancer-specific mortality ( $\mathrm{HR}=2.693$; $\mathrm{P}=0.021$ ). Additionally, in accordance with preclinical data in bladder cancer cells showing enhancement of cisplatin-mediated cytotoxicity by ELK1 inactivation (108), phospho-ELK1 positivity in MI tumors from patients undergoing cisplatin-based neoadjuvant chemotherapy was strongly associated with chemoresistance in subsequent immunohistochemical analysis (91). More recently, we stained for phospho-ELK1 in UUT cancer specimens (109). As with bladder cancers, the expression of phospho-ELK1 in tumors was significantly up-regulated, compared with corresponding non-neoplastic urothelial tissues, and was associated with that of AR. Elevated phospho-ELK1 expression was also marginally $(\mathrm{P}=0.085)$ and significantly $(\mathrm{P}=0.014)$ associated with muscle-invasion (i.e., pT2) and lymphovascular invasion, respectively. Moreover, patients with phospho-ELK1(2+) tumor had a significantly higher risk of cancer-specific mortality $(\mathrm{HR}=3.179$ and $\mathrm{P}=0.013$ in univariate analysis; $\mathrm{HR}=1.131$ and $\mathrm{P}=0.802$ in multivariate analysis), compared to those with phospho-ELK1 (0/1+) tumor.

GATA3 is a member of the GATA family of zinc-finger transcription factors, and its immunohistochemistry, as a marker of urothelial differentiation, has been widely used in diagnostic surgical pathology (110). Loss of GATA3 has been associated with the induction of the development (89) and progression (111) of urothelial cancer. While we demonstrated that androgens could down-regulate GATA3 expression in non-neoplastic urothelial cells, we failed to show comparable effects of estrogens in non-neoplastic urothelial cells or those of androgens in bladder cancer cells $(89,111)$. In our immunohistochemistry in a set of tissue microarray, GATA3 expression was considerably downregulated in the entire group of bladder tumors examined or a subgroup of low-grade/NMI tumors, compared with non-neoplastic urothelial tissues or high-grade/MI tumors, respectively (112). Nonetheless, GATA3 positivity in MI bladder tumors was associated with a significantly higher risk for disease progression even in a multivariate setting (progression: $\mathrm{HR}=2.435$ and $\mathrm{P}=0.052$; cancer-specific survival: $\mathrm{HR}=3.673$ and $\mathrm{P}=0.040$ ). By contrast, a recent study showed a strong association between GATA3 negativity in MI bladder cancers, as an independent predictor, and worse overall survival $(\mathrm{HR}=4.54 ; \mathrm{P}=0.02)(113)$. We also assessed GATA3 expression in UUT urothelial carcinomas and found that GATA3 positivity, as an independent predictor, was associated with higher rates of progressionfree survival in all 99 cases $(\mathrm{HR}=0.479 ; \mathrm{P}=0.051)$ or 62 cases of MI tumors ( $\mathrm{HR}=0.387 ; \mathrm{P}=0.028)$ and those of cancerspecific survival in all cases $(\mathrm{HR}=0.354 ; \mathrm{P}=0.034)$ or $\mathrm{MI}$ tumor cases (HR=0.402; $\mathrm{P}=0.072$ ) (114). In bladder (112) and UUT (114) tumors included in our sets of tissue microarray, there were significant and marginal correlations, respectively, between GATA3 versus AR expression.

$\mathrm{NF}-\kappa \mathrm{B}$, a protein complex of transcription factors consisting of RelA/p65 and others, is known to involve a wide variety of physiological and pathological processes. NF$\kappa \mathrm{B}$ inactivation is also referred to as GR transrepression. We have demonstrated functional interplay between AR and NF$\kappa \mathrm{B}$ signals in non-neoplastic urothelial and bladder cancer cells $(34,37)$. Specifically, androgens could activate NF- $\kappa B$, while NF- $\mathrm{KB}$ activators/inhibitors modulate $\mathrm{AR}$ expression. Preclinical data also indicated that NF- $\kappa \mathrm{B}$ signals induced urothelial tumorigenesis and tumor progression in an ARdependent manner. Immunohistochemical studies have shown elevated nuclear expression of p65 in higher grade or stage bladder cancers $(25,115,116)$. We confirmed these observations and further demonstrated significantly increased expression levels of p65 and its active form phospho-p65 in bladder tumors, compared with corresponding non-neoplastic urothelial tissues (34). Survival analyses in patients with MI bladder cancer in multivariate settings further revealed associations between $\mathrm{p} 65$ overexpression and worse overall survival ( $\mathrm{HR}=1.107 ; \mathrm{P}=0.0003)(115)$ as well as between phospho-p65 positivity and disease progression $(\mathrm{HR}=6.424$; $\mathrm{P}=0.003)$ or cancer-specific mortality $(\mathrm{HR}=4.718 ; \mathrm{P}=0.012)$ (34). In 90 cases of UUT tumors, p65 expression was also found to be an independent predictor of overall survival ( $\mathrm{HR}=2.237 ; \mathrm{P}=0.037)$ or cancer-specific survival $(\mathrm{HR}=2.870$; $\mathrm{P}=0.025$ ) (117). In addition, immunohistochemistry in MI bladder cancer specimens from those who underwent neoadjuvant chemotherapy prior to radical cystectomy showed a strong association of phospho-p65 expression with 
chemoresistance (37).

UGT1A is a key drug-metabolism enzyme especially involving detoxification of bladder carcinogens, including some industrial chemicals and cigarette smoke. It has been shown that androgen-mediated AR signaling and estrogen-mediated ER $\beta$ signaling are associated with reduction and induction, respectively, of the expression levels of UGT1A and its subtypes in SVHUC normal urothelial cells or normal mouse bladders $(47,93)$. An initial immunohistochemical study demonstrated loss of UGT1A in 6 of 19 bladder tumors (118). Subsequent immunohistochemistry demonstrated reduced UGT1A expression in 145 bladder tumors, compared with nonneoplastic urothelial tissues, and inverse associations of UGT1A levels with tumor grade/stage (47). Decreased expression of UGT1A was also associated with the progression of high-grade NMI tumors (only in a univariate setting) or worse cancer-specific survival in patients with MI tumor [even in a multivariate setting $(\mathrm{HR}=3.413 ; \mathrm{P}=0.010)$ ]. In addition, UGT1A expression was positively and negatively correlated with the levels of $\mathrm{ER} \alpha$ and $\mathrm{ER} \beta$, respectively, but not those of AR. In a recent immunohistochemical study in UUT urothelial carcinoma tissues, the expression of UGT1A was down-regulated in tumors, compared with non-neoplastic urothelial tissues, and in MI tumors, compared with NMI tumors (119). Furthermore, UGT1A positivity in M0 tumors was found to be an independent predictor for better cancer-specific survival $(\mathrm{HR}=0.28 ; \mathrm{P}=0.018)$.

\section{Conclusions}

A growing amount of evidence has suggested a critical role of steroid hormone receptor-mediated signals in urothelial tumorigenesis and tumor progression. A variety of molecules, especially downstream targets of $A R$ signaling, have also been shown to involve urothelial cancer outgrowth. Meanwhile, immunohistochemical studies in surgical specimens have revealed significant changes in the expression levels of several steroid hormone receptors and their related proteins in non-neoplastic urothelium versus urothelial tumor as well as in low-grade/NMI versus highgrade/MI urothelial tumors. More importantly, available data support that immunohistochemical detection of some of steroid hormone receptors and related molecules can serve as biomarkers/prognosticators of urothelial tumors, although the underlying mechanisms of how their signals regulate urothelial tumor outgrowth remain poorly understood. Further assessment of steroid hormone receptor signals, as well as other molecules whose expression/activity is directly or indirectly regulated by steroid hormones, may provide not only better strategies for the management of urothelial cancer but also more reliable predictive factors.

\section{Acknowledgments}

Funding: None.

\section{Footnote}

Provenance and Peer Review: This article was commissioned by the Guest Editors (Dr. Ja Hyeon Ku, Dr. Hyeong Dong Yuk, and Dr. Hyung Suk Kim) for the series "Urothelial Carcinoma" published in Translational Cancer Research. The article was sent for external peer review organized by the Guest Editors and the editorial office.

Conflicts of Interest: All authors have completed the ICMJE uniform disclosure form (available at http://dx.doi. org/10.21037/tcr.2020.01.06). The series "Urothelial Carcinoma" was commissioned by the editorial office without any funding or sponsorship. The authors have no other conflicts of interest to declare.

Ethical Statement: The authors are accountable for all aspects of the work in ensuring that questions related to the accuracy or integrity of any part of the work are appropriately investigated and resolved.

Open Access Statement: This is an Open Access article distributed in accordance with the Creative Commons Attribution-NonCommercial-NoDerivs 4.0 International License (CC BY-NC-ND 4.0), which permits the noncommercial replication and distribution of the article with the strict proviso that no changes or edits are made and the original work is properly cited (including links to both the formal publication through the relevant DOI and the license). See: https://creativecommons.org/licenses/by-nc-nd/4.0/.

\section{References}

1. Bray F, Ferlay J, Soerjomataram I, et al. Global cancer statistics 2018: GLOBOCAN estimates of incidence and mortality worldwide for 36 cancers in 185 countries. CA Cancer J Clin 2018;68:394-424.

2. Howlader N, Krapcho AM, Krapcho M, et al. SEER 
Cancer Statistics Review, 1975-2016, National Cancer Institute. Bethesda, MD Available online: https://seer. cancer.gov/csr/1975_2016/ based on November 2018 SEER data submission, posted to the SEER web site, April 2019.

3. Boorjian S, Ugras S, Mongan NP, et al. Androgen receptor expression is inversely correlated with pathologic tumor stage in bladder cancer. Urology 2004;64:383-8.

4. Boorjian SA, Heemers HV, Frank I, et al. Expression and significance of androgen receptor coactivators in urothelial carcinoma of the bladder. Endocr Relat Cancer 2009;16:123-37.

5. Kauffman EC, Robinson BD, Downes MJ, et al. Role of androgen receptor and associated lysine-demethylase coregulators, LSD1 and JMJD2A, in localized and advanced human bladder cancer. Mol Carcinog 2011;50:931-44.

6. Mir C, Shariat SF, van der Kwast TH, et al. Loss of androgen receptor expression is not associated with pathological stage, grade, gender or outcome in bladder cancer: a large multi-institutional study. BJU Int 2011;108:24-30.

7. Rau KM, Chen YJ, Sun MT, et al. Prognostic effects and regulation of activin $\mathrm{A}$, maspin, and the androgen receptor in upper urinary tract urothelial carcinoma. Anticancer Res 2011;31:1713-20.

8. Tuygun C, Kankaya D, Imamoglu A, et al. Sex-specific hormone receptors in urothelial carcinomas of the human urinary bladder: a comparative analysis of clinicopathological features and survival outcomes according to receptor expression. Urol Oncol 2011;29:43-51.

9. Miyamoto H, Yao JL, Chaux A, et al. Expression of androgen and oestrogen receptors and its prognostic significance in urothelial neoplasm of the urinary bladder. BJU Int 2012;109:1716-26.

10. Shyr CR, Chen CC, Hsieh TF, et al. The expression and actions of androgen receptor in upper urinary tract urothelial carcinoma (UUTUC) tissues and the primary cultured cells. Endocrine 2013;43:191-9.

11. Jing Y, Cui D, Guo W, et al. Activated androgen receptor promotes bladder cancer metastasis via Slug mediated epithelial-mesenchymal transition. Cancer Lett 2014;348:135-45.

12. Mashhadi R, Pourmand G, Kosari F, et al. Role of steroid hormone receptors in formation and progression of bladder carcinoma: a case-control study. Urol J 2014;11:1968-73.

13. Nam JK, Park SW, Lee SD, et al. Prognostic value of sexhormone receptor expression in NMI bladder cancer.
Yonsei Med J 2014;55:1214-21.

14. Williams EM, Higgins JP, Sangoi AR, et al. Androgen receptor immunohistochemistry in genitourinary neoplasms. Int Urol Nephrol 2015;47:81-5.

15. Kashiwagi E, Fujita K, Yamaguchi S, et al. Expression of steroid hormone receptors and its prognostic significance in urothelial carcinoma of the upper urinary tract. Cancer Biol Ther 2016;17:1188-96.

16. Wirth GJ, Haitel A, Moschini M, et al. Androgen receptor expression is associated with adverse pathological features in ureteral but not in pelvicalyceal urothelial carcinomas of the upper urinary tract. World J Urol 2017;35:943-9.

17. Elzamy S, Ms AA, Kandeel W. The prognostic significance of androgen receptor and $\beta$-catenin immunohistochemical expression in urothelial carcinoma with and without detrusor muscle invasion from an Egyptian institution. Pol J Pathol 2018;69:234-42.

18. Necchi A, Lo Vullo S, Giannatempo P, et al. Association of androgen receptor expression on tumor cells and PDL1 expression in muscle-invasive and metastatic urothelial carcinoma: Insights for clinical research. Clin Genitourin Cancer 2018;16:e403-10.

19. Tyagi A, Chandrasekaran B, Kolluru V, et al. Combination of androgen receptor inhibitor and cisplatin, an effective treatment strategy for urothelial carcinoma of the bladder. Urol Oncol 2019;37:492-502.

20. Yonekura S, Terauchi F, Hoshi K, et al. Androgen receptor predicts first and multiple recurrences in non-muscle invasive urothelial carcinoma of the bladder. Pathol Oncol Res 2019;25:987-94.

21. Shen SS, Smith CL, Hsieh JT, et al. Expression of estrogen receptors- $\alpha$ and $-\beta$ in bladder cancer cell lines and human bladder tumor tissue. Cancer 2006;106:2610-6.

22. Bolenz C, Lotan Y, Ashfaq R, et al. Estrogen and progesterone hormonal receptor expression in urothelial carcinoma of the bladder. Eur Urol 2009;56:1093-5.

23. Tan W, Boorjian S, Advani P, et al. The estrogen pathway: estrogen receptor- $\alpha$, progesterone receptor, and estrogen receptor- $\beta$ expression in radical cystectomy urothelial cell carcinoma specimens. Clin Genitourin Cancer 2015;13:476-84.

24. Croft PR, Lathrop SL, Feddersen RM, et al. Estrogen receptor expression in papillary urothelial carcinoma of the bladder and ovarian transitional cell carcinoma. Arch Pathol Lab Med 2005;129:194-9.

25. Kontos S, Kominea A, Melachrinou M, et al. Inverse expression of estrogen receptor- $\beta$ and nuclear factor- $\kappa \mathrm{B}$ in urinary bladder carcinogenesis. Int J Urol 2010;17:801-9. 
26. Kauffman EC, Robinson BD, Downes M, et al. Estrogen receptor- $\beta$ expression and pharmacological targeting in bladder cancer. Oncol Rep 2013;30:131-8.

27. Luo HL, Sung MT, Tsai EM, et al. Expression of estrogen receptor beta predicts oncologic outcome of pT3 upper urinary tract urothelial carcinoma better than aggressive pathological features. Sci Rep 2016;6:24263.

28. Ishiguro H, Kawahara T, Zheng Y, et al. Reduced glucocorticoid receptor expression predicts bladder tumor recurrence and progression. Am J Clin Pathol 2014;142:157-64.

29. Inoue S, Mizushima T, Miyamoto H. Role of the androgen receptor in urothelial cancer. Mol Cell Endocrinol 2018;465:73-81.

30. Izumi K, Taguri M, Miyamoto H, et al. Androgen deprivation therapy prevents bladder cancer recurrence. Oncotarget 2014;5:12665-74.

31. Shiota M, Yokomizo A, Takeuchi A, et al. Secondary bladder cancer after anticancer therapy for prostate cancer: reduced comorbidity after androgen-deprivation therapy. Oncotarget 2015;6:14710-9.

32. Izumi K, Ito Y, Miyamoto H, et al. Expression of androgen receptor in NMI bladder cancer predicts the preventive effect of androgen deprivation therapy on tumor recurrence. Oncotarget 2016;7:14153-60.

33. Shiota M, Kiyoshima K, Yokomizo A, et al. Suppressed recurrent bladder cancer after androgen suppression with androgen deprivation therapy or $5 \alpha$-reductase inhibitor. J Urol 2017;197:308-13.

34. Inoue $\mathrm{S}$, Ide $\mathrm{H}$, Mizushima $\mathrm{T}$, et al. Nuclear factor- $\kappa \mathrm{B}$ promotes urothelial tumorigenesis and cancer progression via cooperation with androgen receptor signaling. Mol Cancer Ther 2018;17:1303-14.

35. Inoue $\mathrm{S}$, Mizushima $\mathrm{T}$, Ide $\mathrm{H}$, et al. ATF2 promotes urothelial cancer outgrowth via cooperation with androgen receptor signaling. Endocr Connect 2018;7:1397-408.

36. Ide H, Inoue S, Miyamoto H. Histopathological and prognostic significance of the expression of sex hormone receptors in bladder cancer: A metaanalysis of immunohistochemical studies. PLoS One 2017;12:e0174746.

37. Kashiwagi E, Ide H, Inoue S, et al. Androgen receptor activity modulates responses to cisplatin treatment in bladder cancer. Oncotarget 2016;7:49169-79.

38. Mizushima T, Jiang G, Kawahara T, et al. Androgen receptor signaling reduces direct cytotoxicity of bacillus Calmette-Guérin (BCG) in bladder cancer cells via modulating Rab27b. J Urol 2019;201:e815-6.
39. Erben P, Sikic D, Wirtz RM, et al. Analysis of the prognostic relevance of sex-steroid hormonal receptor mRNA expression in muscle-invasive urothelial carcinoma of the urinary bladder. Virchows Arch 2019;474:209-17.

40. Sikic D, Wirtz RM, Wach S, et al. Androgen receptor mRNA expression in urothelial carcinoma of the bladder: A retrospective analysis of two independent cohorts. Transl Oncol 2019;12:661-8.

41. Kim HT, Kim BC, Kim IY, et al. Raloxifene, a mixed estrogen agonist/antagonist, induces apoptosis through cleavage of BAD in TSU-PR1 human cancer cells. J Biol Chem 2002;277:32510-5.

42. Waalkes MP, Liu J, Ward JM, et al. Urogenital carcinogenesis in female CD1 mice induced by in utero arsenic exposure is exacerbated by postnatal diethylstilbestrol treatment. Cancer Res 2006;66:1337-45.

43. Sonpavde G, Okuno N, Weiss H, et al. Efficacy of selective estrogen receptor modulators in nude mice bearing human transitional cell carcinoma. Urology 2007;69:1221-6.

44. Teng J, Wang ZY, Jarrard DF, et al. Roles of estrogen receptor alpha and beta in modulating urothelial cell proliferation. Endocr Relat Cancer 2008;15:351-64.

45. Miyamoto H, Zheng Y, Izumi K. Nuclear hormone receptor signals as new therapeutic targets for urothelial carcinoma. Curr Cancer Drug Targets 2012;12:14-22.

46. Hsu I, Vitkus S, Da J, et al. Role of oestrogen receptors in bladder cancer development. Nat Rev Urol 2013;10:317-26.

47. Izumi K, Li Y, Ishiguro H, et al. Expression of UDPglucuronosyltransferase 1A in bladder cancer: association with prognosis and regulation by estrogen. Mol Carcinog 2014;53:314-24.

48. Hsu I, Yeh CR, Slavin S, et al. Estrogen receptor alpha prevents bladder cancer via INPP4B inhibited akt pathway in vitro and in vivo. Oncotarget 2014;5:7917-35.

49. Huang W, Chen Y, Liu Y, et al. Roles of ER $\beta$ and GPR30 in proliferative response of human bladder cancer cell to estrogen. Biomed Res Int 2015;2015:251780.

50. Dietrich K, Schned A, Fortuny J, et al. Glucocorticoid therapy and risk of bladder cancer. Br J Cancer 2009;101:1316-20.

51. Ide H, Inoue S, Mizushima T, et al. Role of glucocorticoid signaling in urothelial tumorigenesis: Inhibition by prednisone presumably through inducing glucocorticoid receptor transrepression. Mol Carcinog 2019;58:2297-305.

52. Zheng Y, Izumi K, Li Y, et al. Contrary regulation of bladder cancer cell proliferation and invasion by dexamethasone-mediated glucocorticoid receptor signals. Mol Cancer Ther 2012;11:2621-32. 
53. Ishiguro H, Kawahara T, Zheng Y, et al. Differential regulation of bladder cancer growth by various glucocorticoids: Corticosterone and prednisone inhibit cell invasion without promoting cell proliferation or reducing cisplatin cytotoxicity. Cancer Chemother Pharmacol 2014;74:249-55.

54. Ide $\mathrm{H}$, Inoue $\mathrm{S}$, Miyamoto $\mathrm{H}$. The role of glucocorticoid receptor signaling in bladder cancer progression. Cancers 2018;10:484.

55. Zheng $\mathrm{Y}$, Ishiguro $\mathrm{H}$, Ide $\mathrm{H}$, et al. Compound $\mathrm{A}$ inhibits bladder cancer growth predominantly via glucocorticoid receptor transrepression. Mol Endocrinol 2015;29:1486-97.

56. Wolpert BJ, Amr S, Ezzat S, et al. Estrogen exposure and bladder cancer risk in Egyptian women. Maturitas 2010;67:353-7.

57. Johnson AM, O'Connell MJ, Messing EM, et al. Decreased bladder cancer growth in parous mice. Urology 2008;72:470-3.

58. Noronha RF, Rao BR. Sex hormone receptors in localized and advanced transitional cell carcinoma of urinary tract in humans. Urology 1986;28:401-3.

59. Celayir S, Ilçe Z, Dervisoglu S. The sex hormone receptors in the bladder in childhood - I: preliminary report in male subjects. Eur J Pediatr Surg 2002;12:312-7.

60. Baykan O, Akgul M, Uren N, et al. The relationship between urothelial type bladder cancer, plasma 25-hydroxyvitamin D levels, and vitamin D receptor ApaI BsmI FokI, and TaqI polymorphisms. Clin lab 2019;65:180339.

61. Liao Y, Huang JL, Qiu MX, et al. Impact of serum vitamin $\mathrm{D}$ level on risk of bladder cancer: a systemic review and meta-analysis. Tumour Biol 2015;36:1567-72.

62. Ben Fradj MK, Kallel A, Gargouri MM, et al. Association of FokI polymorphism of vitamin D receptor with urothelial bladder cancer in Tunisians: role of tobacco smoking and plasma vitamin D concentration. Tumour Biol 2016;37:6197-203.

63. Konety BR, Lavelle JP, Pirtskalaishvili G, et al. Effects of vitamin $\mathrm{D}$ (calcitriol) on transitional cell carcinoma of the bladder in vitro and in vivo. J Urol 2001;165:253-8.

64. Hermann GG, Andersen CB. Transitional cell carcinoma express vitamin D receptors. Scand J Urol Nephrol 1997;31:161-6.

65. Sahin MO, Canda AE, Yorukoglu K, et al. 1,25 Dihydroxyvitamin D3 receptor expression in superficial transitional cell carcinoma of the bladder: a possible prognostic factor?. Eur Urol 2005;47:52-7.

66. Jóźwicki W, Brożyna AA, Siekiera J, et al. Expression of vitamin D receptor (VDR) positively correlates with survival of urothelial bladder cancer patients. Int J Mol Sci 2015;16:24369-86.

67. Tang JE, Wang RJ, Zhong H, et al. Vitamin A and risk of bladder cancer: a meta-analysis of epidemiological studies. World J Surg Oncol 2014;12:130.

68. Becci PJ, Thompson HJ, Grubbs CJ, et al. Inhibitory effect of 13-cis-retinoic acid on urinary bladder carcinogenesis induced in C57BL/6 mice by N-butyl-N-(4-hydroxybutyl)nitrosamine. Cancer Res 1978;38:4463-6.

69. Zou C, Zhou J, Qian L, et al. Comparing the effect of ATRA, 4-HPR, and CD437 in bladder cancer cells. Front Biosci 2006;11:2007-16.

70. Boorjian S, Scherr DS, Mongan NP, et al. Retinoid receptor mRNA expression profiles in human bladder cancer specimens. Int J Oncol 2005;26:1041-8.

71. Maldonado L, Brait M, Michailidi C, et al. An epigenetic marker panel for recurrence risk prediction of low grade papillary urothelial cell carcinoma (LGPUCC) and its potential use for surveillance after transurethral resection using urine. Oncotarget 2014;5:5218-33.

72. Yan H, Xie H, Ying Y, et al. Pioglitazone use in patients with diabetes and risk of bladder cancer: a systematic review and meta-analysis. Cancer Manag Res 2018;10:1627-38.

73. Tang H, Shi W, Fu S, et al. Pioglitazone and bladder cancer risk: a systematic review and meta-analysis. Cancer Med 2018;7:1070-80.

74. Yang DR, Lin SJ, Ding XF, et al. Higher expression of peroxisome proliferator-activated receptor $\gamma$ or its activation by agonist thiazolidinedione-rosiglitazone promotes bladder cancer cell migration and invasion. Urology 2013;81:1109.e1-6.

75. Kassouf W, Chintharlapalli S, Abdelrahim M, et al. Inhibition of bladder tumor growth by 1,1-bis(3'indolyl)-1-(p-substitutedphenyl)methanes: a new class of peroxisome proliferator-activated receptor gamma agonists. Cancer Res 2006;66:412-8.

76. Wei S, Yang J, Lee SL, et al. PPAR $\gamma$-independent antitumor effects of thiazolidinediones. Cancer Lett 2009;276:119-24

77. Yang SL, Wang JJ, Chen M, et al. Pioglitazone use and risk of bladder cancer: an in vitro study. Int J Med Sci 2018;15:228-37.

78. Okegawa T, Ushio K, Imai M, et al. Orphan nuclear receptor HNF4G promotes bladder cancer growth and invasion through the regulation of the hyaluronan synthase 2 gene. Oncogenesis 2013;2:e58. 
79. Sun H, Tian J, Xian W, et al. miR-34a inhibits proliferation and invasion of bladder cancer cells by targeting orphan nuclear receptor HNF4G. Dis Markers 2015;2015:879254.

80. Inamoto T, Czerniak BA, Dinney CP, et al. Cytoplasmic mislocalization of the orphan nuclear receptor Nurr1 is a prognostic factor in bladder cancer. Cancer 2010;116:340-6.

81. Cho SD, Lee SO, Chintharlapalli S, et al. Activation of nerve growth factor-induced B alpha by methylenesubstituted diindolylmethanes in bladder cancer cells induces apoptosis and inhibits tumor growth. Mol Pharmacol 2010;77:396-404.

82. Wu J, Liu J, Jia R, et al. Nur77 inhibits androgen-induced bladder cancer growth. Cancer Invest 2013;31:654-60.

83. Zheng Y, Izumi K, Yao JL, et al. Dihydrotestosterone upregulates the expression of epidermal growth factor receptor and ERBB2 in androgen receptor-positive bladder cancer cells. Endocr Relat Cancer 2011;18:451-64.

84. Li Y, Zheng Y, Izumi K, et al. Androgen activates $\beta$-catenin signaling in bladder cancer cells. Endocr Relat Cancer 2013;20:293-304.

85. Lin C, Yin Y, Stemler K, et al. Constitutive $\beta$-catenin activation induces male-specific tumorigenesis in the bladder urothelium. Cancer Res 2013;73:5914-25.

86. Wu JT, Han BM, Yu SQ, et al. Androgen receptor is a potential therapeutic target for bladder cancer. Urology 2010;75:820-7.

87. Overdevest JB, Knubel KH, Duex JE, et al. CD24 expression is important in male urothelial tumorigenesis and metastasis in mice and is androgen regulated. Proc Natl Acad Sci USA 2012;109:E3588-96.

88. Agarwal N, Dancik GM, Goodspeed A, et al. GON4L drives cancer growth through a YY1-androgen receptorCD24 axis. Cancer Res 2016;76:5175-85.

89. Li Y, Ishiguro H, Kawahara T, et al. GATA3 in the urinary bladder: suppression of neoplastic transformation and down-regulation by androgens. Am J Cancer Res 2014;4:461-73.

90. Kawahara T, Shareef HK, Aljarah AK, et al. ELK1 is upregulated by androgen in bladder cancer cells and promotes tumor progression. Oncotarget 2015;6:29860-76.

91. Inoue S, Ide H, Mizushima T, et al. ELK1 promotes urothelial tumorigenesis in the presence of an activated androgen receptor. Am J Cancer Res. 2018;8:2325-36.

92. Hsu JW, Hsu I, Xu D, et al. Decreased tumorigenesis and mortality from bladder cancer in mice lacking urothelial androgen receptor. Am J Pathol 2013;182:1811-20.

93. Izumi K, Zheng Y, Hsu JW, et al. Androgen receptor signals regulate UDP-glucuronosyltransferases in the urinary bladder: a potential mechanism of androgen-induced bladder carcinogenesis. Mol Carcinog 2013;52:94-102.

94. Garcia del Muro X, Torregrosa A, Muñoz J, et al. Prognostic value of the expression of E-cadherin and $\beta$-catenin in bladder cancer. Eur J Cancer 2000;36:357-62.

95. Zhu X, Kanai Y, Saito A, et al. Aberrant expression of $\beta$-catenin and mutation of exon 3 of the $\beta$-catenin gene in renal and urothelial carcinomas. Pathol Int 2000;50:945-52.

96. Kastritis E, Murray S, Kyriakou F, et al. Somatic mutations of adenomatous polyposis coli gene and nuclear b-catenin accumulation have prognostic significance in invasive urothelial carcinomas: evidence for Wnt pathway implication. Int J Cancer 2009;124:103-8.

97. Senol S, Yildirim A, Ceyran B, et al. Prognostic significance of survivin, $\beta$-catenin and $\mathrm{p} 53$ expression in urothelial carcinoma. Bosn J Basic Med Sci 2015;15:7-14.

98. Overdevest JB, Thomas S, Kristiansen G, et al. CD24 offers a therapeutic target for control of bladder cancer metastasis based on a requirement for lung colonization. Cancer Res 2011;71:3802-11.

99. Liu C, Zheng S, Shen H, et al. Clinical significance of $\mathrm{CD} 24$ as a predictor of bladder cancer recurrence. Oncol Lett 2013;6:96-100.

100.Hofner T, Macher-Goeppinger S, Klein C, et al. Expression and prognostic significance of cancer stem cell markers CD24 and CD44 in urothelial bladder cancer xenografts and patients undergoing radical cystectomy. Urol Oncol 2014;32:678-86.

101.Mooso BA, Vinall RL, Mudryj M, et al. The role of EGFR family inhibitors in muscle invasive bladder cancer: a review of clinical data and molecular evidence. J Urol 2015;193:19-29.

102.Izumi K, Zheng Y, Li Y, et al. Epidermal growth factor induces bladder cancer cell proliferation through activation of the androgen receptor. Int J Oncol 2012;41:1587-92.

103.de Martino M, Zhuang D, Klatte T, et al. Impact of ERBB2 mutations on in vitro sensitivity of bladder cancer to lapatinib. Cancer Biol Ther 2014;15:1239-47.

104.Zhao J, Xu W, Zhang Z, et al. Prognostic role of HER2 expression in bladder cancer: a systematic review and meta-analysis Int Urol Nephrol 2015;47:87-94.

105. Groenendijk FH, de Jong J, Fransen van de Putte EE, et al. ERBB2 mutations characterize a subgroup of muscleinvasive bladder cancers with excellent response to neoadjuvant chemotherapy. Eur Urol 2016;69:384-8.

106. Tschui J, Vassella E, Bandi N, et al. Morphological and molecular characteristics of HER2 amplified urothelial 
bladder cancer. Virchows Arch 2015;466:703-10.

107. Soria F, Moschini M, Haitel A, et al. The effect of HER2 status on oncological outcomes of patients with invasive bladder cancer. Urol Oncol 2016;34:533.e1-10.

108. Kawahara T, Ide H, Kashiwagi E, et al. Silodosin inhibits the growth of bladder cancer cells and enhances the cytotoxic activity of cisplatin via ELK1 inactivation. Am J Cancer Res 2015;5:2959-68.

109. Inoue S, Ide H, Fujita K, et al. Expression of phosphoELK1 and its prognostic significance in urothelial carcinoma of the upper urinary tract. Int J Mol Sci 2018;19:E777.

110.Amin MB, Trpkov K, Lopez-Beltran A, et al. Best practices recommendations in the application of immunohistochemistry in the bladder lesions: report from the International Society of Urologic Pathology Consensus Conference. Am J Surg Pathol 2014:38:e20-34.

111.Li Y, Ishiguro H, Kawahara T, et al. Loss of GATA3 in bladder cancer promotes cell migration and invasion. Cancer Biol Ther 2014;15:428-35.

112. Miyamoto H, Izumi K, Yao JL, et al. GATA binding protein 3 is down-regulated in bladder cancer yet strong expression is an independent predictor of poor prognosis in invasive tumor. Hum Pathol 2012;43:2033-40.

113.Jangir H, Nambirajan A, Seth A, et al. Prognostic stratification of muscle invasive urothelial carcinomas using limited immunohistochemical panel of Gata3

Cite this article as: Nagata Y, Miyamoto H. The prognostic role of steroid hormone receptor signaling pathways in urothelial carcinoma. Transl Cancer Res 2020;9(10):6596-6608. doi: 10.21037/tcr.2019.01.06 and cytokeratins 5/6, 14 and 20. Ann Diagn Pathol 2019;43:151397.

114. Inoue S, Mizushima T, Fujita K, et al. GATA3 immunohistochemistry in urothelial carcinoma of the upper urinary tract as a urothelial marker and a prognosticator. Hum Pathol 2017;64:83-90.

115.Levidou G, Saetta AA, Korkolopoulou P, et al. Clinical significance of nuclear factor (NF)- $\kappa \mathrm{B}$ levels in urothelial carcinoma of the urinary bladder. Virchows Arch 2008;452:295-304.

116.Zheng J, Kong C, Yang X, et al. Protein kinase C- $\alpha$ $(\mathrm{PKC} \alpha)$ modulates cell apoptosis by stimulating nuclear translocation of NF-kappa-B p65 in urothelial cell carcinoma of the bladder. BMC Cancer 2017;17:432.

117. Yeh HC, Huang CH, Yang SF, et al. Nuclear factor$\kappa \mathrm{B}$ activation predicts an unfavourable outcome in human upper urinary tract urothelial carcinoma. BJU Int 2010;106:1223-9.

118. Giuliani L, Ciotti M, Stoppacciaro A, et al. UDPglucuronosyltransferases $1 \mathrm{~A}$ expression in human urinary bladder and colon cancer by immunohistochemistry. Oncol Rep 2005;13:185-91.

119. Izumi K, Inoue S, Ide H, et al. Uridine 5'diphosphoglucuronosyltransferase 1A expression as an independent prognosticator in urothelial carcinoma of the upper urinary tract. Int J Urol 2018;25:429-35. 